\title{
Purchasing Strategies, Tactics, and Activities in Engineer-to-Order Manufacturing
}

\author{
Mikhail Shlopak ${ }^{\bowtie}$, Espen Rød and Gabriele Hofinger Jünge \\ Møreforsking Molde AS, Molde, Norway \\ (mikhail.shlopak, espen.rod, gabriele.h.junge)@ himolde.no
}

\begin{abstract}
This paper presents a six-step method for matching strategic purchasing goals with relevant tactics and operationalizing them through specific activities. The paper provides some of the observations from three Norwegian engineer-to-order companies that are currently working on implementing the proposed method. This paper contributes to purchasing and supply chain management research by providing and testing a method that helps companies to develop strategic goals for different segments of their purchasing portfolios and to match them with relevant tactics and specific activities.
\end{abstract}

Keywords: supply chain management (SCM), purchasing, engineer-to-order (ETO)

\section{Introduction}

A supply chain is managed, link-by-link, relationship-by-relationship and the organizations that manage these relationships best will win [1].

Manufacturing strategies usually relate to the point where a particular product is linked to a specific customer. A common strategy is to make the distinction among make-tostock (MTS), assemble-to-order (ATO), make-to-order (MTO), and engineer-to-order (ETO) production [2]. ETO companies can be identified by their characteristics of supplying high-value, customized products and having a deep and complex structure, and the general view is that the ETO supply chain is where the "decoupling point" is located at the design stage [3].

In the past, researchers built their theories on the assumption that companies competed with one another. This thinking was later replaced by the idea that supply chains, not individual companies, competed with one another. More recently, this understanding has evolved further due to the realization that companies often have similar supply chains and share many of the same suppliers. This means that companies compete on managing the links or relationships in their supply chains [1].

Therefore, successful ETO manufacturing depends on the effective management of supply chain relationships. The purpose of this paper is to describe the method for ETO companies to develop purchasing strategies, tactics, and activities based on the analysis 
of their purchasing portfolios in order to improve supply chain relationship management.

\section{Theoretical Background}

Various scholars [4-10] have described ETO characteristics and operations as inherently different from those of mass production. This paper's scope emphasizes the complexity of ETO manufacturing, derived from three characteristics.

First, ETO manufacturing produces capital goods that are typically high-value due to their uniqueness and complexity, and they are delivered as projects [7, 9, 11, 12]. Therefore, supplier networks are built temporarily and torn down after project fulfillment.

Second, ETO manufacturing combines non-physical activities, such as design and engineering [7, 13,14], with physical activities, such as component production, assembly, and installation [5]. The non-physical activities are often geographically dispersed, separated from physical activities, and executed by individual entities. Consequently, the company that manages the overall project executes only a small part of the project that is performed by its own personnel and in its own production facilities.

Third, ETO manufacturing often executes engineering and production concurrently because not all design details and drawings are finalized when the procurement of longlead items and the production of the components start. Accordingly, design changes affect component production at all supplier tiers, making it difficult to align and control production and engineering activities. Quality issues may arise, requiring rework $[8$, 15-18].

Therefore, successful ETO manufacturing depends on the effective management of supply chain relationships. Among the most known frameworks for managing supply chain relationships are the $\mathrm{ABC}$ analysis and different varieties of purchasing portfolio models originated by Peter Kraljic [19]. The ABC analysis is a well-known tool for differentiating between important and less important purchases, but it merely focuses on the financial value of each purchase [20].

A wide variety of purchasing portfolio models inspired by the Kraljic matrix can be utilized to execute a purchasing portfolio analysis (PPA). However, all of these models are very similar to the original Kraljic matrix in that they use almost the same dimensions and suggest similar tactics [20]. This is why, in this paper, the PPA implies, in line with the original Kraljic model, the classification of purchased items into four categories in a $2 \times 2$ matrix: strategic, bottleneck, leverage, and noncritical. In contrast to the $\mathrm{ABC}$ analysis, the PPA is based on two dimensions: supply risk and financial impact [20]. This more balanced approach to differentiating a company's purchases is the reason why this study applies the PPA. The PPA allows ETO companies to analyze and understand their purchasing portfolios, thus setting them in a position to develop purchasing strategies and tactical initiatives.

A purchasing strategy can be described as a strategic approach related to the purchasing department [21-24]. The purchasing strategy can be defined in the form of strategic priorities, such as costs, flexibility, and innovations. Purchasing tactics, or what 
is called "sourcing levers" [23], comprise a set of tactics used to operationalize the purchasing strategy as a combination of activities in a purchasing category. Purchasing tactics directly address the actions that decision makers can take to achieve the desired outcomes. The tactics can be divided into two groups: transaction-oriented tactics, which focus on capturing the existing value, and relationship-oriented tactics, which emphasize creating value in collaboration with other actors [23] (Table 1).

Table 1. Purchasing tactics [23]

\begin{tabular}{ll}
\hline Transaction-oriented tactics & Relationship-oriented tactics \\
\hline Volume bundling & Product optimization \\
Price evaluation & Process optimization \\
Extension of supply base & Optimization of supply relationships \\
& Category-spanned optimization \\
\hline
\end{tabular}

Once the tactics are identified, they are further broken down into a set of specific activities to realize the strategic goals [23].

\section{$3 \quad$ Research Methodology}

Case studies are widely used in operations management research to test, develop, and extend theories [25, 26]. This paper applies a multiple case study approach as it is likely to build a more robust and testable theory than a single case would. The empirical basis for this study is based on multiple representative case studies involving three Norwegian ETO-manufacturing companies [27, 28]. Company A produces customized, capital-intensive, and advanced products for the maritime industry; company B produces one-of-a-kind, highly technical, and complex products for the global oil and gas industry; and company $\mathrm{C}$ produces customized hydraulic products for a broad range of market segments and industries. Although these companies operate in different market segments, all of them have their own production facilities in Norway, and over $60 \%$ of the costs of their final products come from purchased items and services.

Consequently, the three ETO companies in this study are involved in different ongoing research projects focusing on the improvement of delivery time and delivery precision through better supply chain relationship management. The main data was collected from workshops, focused interviews, and observations, as well as from discussions and site visits over a 14-month period. The data analysis was carried out by three researchers in close cooperation with key personnel of the three case companies. Application of ideas and best practices from the review of relevant literature (in particular [21-24]) and resulting active discussion with three case companies, allowed the conceptualizing of a six-step methodology. 


\section{Developing Strategies, Tactics, and Activities}

Based on the discussed literature and the empirical investigation, this paper suggests a six-step method to develop purchasing strategies, tactics, and activities (Figure 1):

1. Develop strategic goals for each quadrant in the PPA.

2. Select the relevant tactics for each product category.

3. Identify the activities for each tactic.

4. Evaluate and prioritize the activities.

5. Execute the prioritized activities.

6. Evaluate the effects of the executed activities.

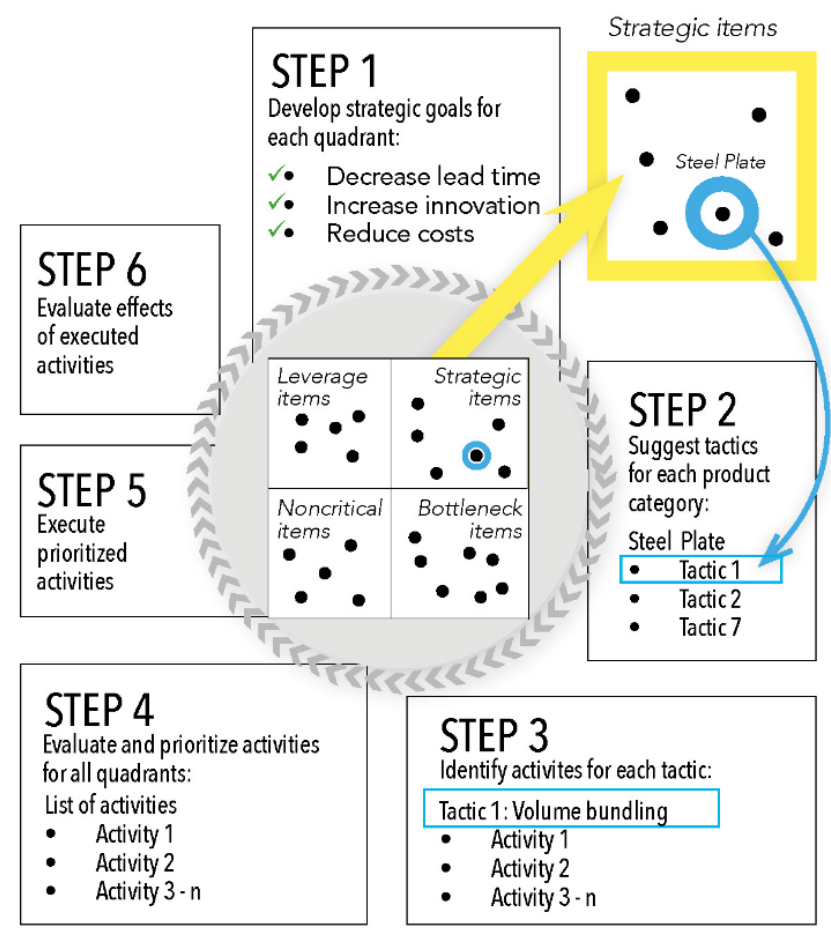

Fig. 1. Six-step method for developing purchasing strategies, tactics and activities

The proposed method implies that a company has already performed the PPA. It is worth mentioning that this methodology can easily be adapted to fit the output of other ways of categorizing a company's purchasing portfolio, such as the $\mathrm{ABC}$ analysis. The following sections provide a more detailed description of these steps. 


\subsection{Develop Strategic Goals for Each Quadrant in the PPA}

As explained earlier, purchasing strategies are defined in the form of strategic priorities, such as costs, flexibility, or innovations. In step 1, the goal is to agree on one or more strategic goals or priorities for each quadrant in the matrix (strategic, bottleneck, leverage, and noncritical). A strategic goal/priority could be reduced costs, reduced lead times, increased delivery performance, increased innovations, and so on. For example, a company could select a strategic goal of $10 \%$ cost reduction for all purchasing categories in the noncritical quadrant, $95 \%$ delivery precision for all purchasing categories in the strategic quadrant, and $20 \%$ lead time reduction for all purchasing categories in the bottleneck quadrant.

\subsection{Select the Relevant Tactics for Each Product Category}

Step 2 involves selecting the relevant tactics for each product category in each quadrant. The strategic goals/priorities determined in step 1 should guide the choice of relevant tactics, as listed in Table 1. For instance, a company may choose the volume bundling and the price evaluation tactics to underpin its strategic goal of $10 \%$ cost reduction for the sealing rings purchasing category in the noncritical quadrant of the matrix.

\subsection{Identify the Activities for Each Tactic}

In step 3, a company identifies the activities for each of the tactics chosen in step 2. Following the example in step 2, the specific activities aimed at operationalizing the volume bundling tactic for the sealing rings purchasing category could be concentrating the volumes on suppliers $X$ and $Y$ and bundling several requests into a package with $a$ large volume.

\subsection{Evaluate and Prioritize the Activities}

As the activities can vary significantly in terms of time, cost, ease of execution, risk, and so on, it is necessary to evaluate all activities for all product categories and prioritize those activities that should be executed (step 4). Depending on the purchasing portfolio, some companies can end up with several hundred activities. The process of evaluating and prioritizing can be tedious and challenging. Therefore, the authors suggest that a structured set of evaluation criteria is needed, and more research on this matter is welcome.

\subsection{Execute the Prioritized Activities}

Step 5 entails the execution of the activities, following the prioritization in step 4 .

\subsection{Evaluate the Effects of the Executed Activities}

In the final step, a company should evaluate the effects of the executed activities on the strategic goals defined in step 1, as well as on the positioning of specific purchasing categories in the matrix, as it is likely that some of them could move to another quadrant 
due to changes in their supply risk and financial impact scores. In addition, as ETOmanufacturers work in project-based environment, each new project introduces several new purchasing categories in the company's purchasing portfolio. Therefore, at this point, it is natural for the loop to start again, beginning with adjusting the strategic goals for each quadrant, all the way through to executing the newly prioritized activities, evaluating their effects, and so on. As a result, this approach forces a company to continuously work on its purchasing portfolio by developing and adjusting its strategic goals, selecting the relevant tactics, prioritizing and testing specific activities, and evaluating their effects.

\section{Discussion}

This section briefly discusses some of the observations from the three case companies that are currently working on implementing the proposed method described in section 4. At the time of writing this paper, the current project status of each case company is somewhere between steps 2 and 3 of the proposed method.

In step 1 (develop strategic goals for each quadrant in the PPA), it was common for all of the companies to focus on reducing purchasing costs, increasing the delivery precision, and/or reducing the lead time for all quadrants in their PPAs.

In step 2 (select the relevant tactics for each product category), all of the companies selected a combination of both transaction-oriented and relationship-oriented tactics (see Table 1). For example, one of the companies chose volume bundling, process optimization, and optimization of supplier relationships as the common tactics for each of the purchasing categories in the strategic quadrant. However, the same company used a more tailored approach to selecting the relevant tactics for each of the five purchasing categories in the bottleneck quadrant. Price evaluation was a common tactic for all of these purchasing categories, but selection of other tactics, such as process optimization and volume bundling, differed.

In step 3, the selected tactics are currently being operationalized by connecting them with specific activities. For instance, one of the companies has selected the test delivery from supplier $Z$ activity for the toothed ring purchasing category to operationalize its selected tactic extension of supply base, underpinning its strategic goals of reduced purchasing costs and increased delivery precision for the purchasing categories in the strategic quadrant.

As mentioned earlier, the lists of activities by each case company will likely include several hundred lines. A structured approach for prioritizing which of the activities should be executed first is needed.

\section{Conclusion}

To improve the supply chain relationship management in ETO manufacturing, a method for developing purchasing strategies, tactics, and activities was designed. The method was developed in cooperation with three Norwegian ETO companies. 
This paper contributes to purchasing and supply chain management research by providing and testing a method that helps ETO companies to develop strategic goals for different segments of their purchasing portfolios and to match them with relevant tactics and specific activities.

Funding and acknowledgments. The Norwegian Research Council funded this study. The authors express their appreciation to the case companies.

\section{References}

1. Lambert, D.M. and M.G. Enz, Issues in supply chain management: Progress and potential. Industrial Marketing Management, 2017. 62: p. 1-16.

2. Olhager, J., Strategic positioning of the order penetration point. International Journal of Production Economics, 2003. 85(3): p. 319-329.

3. Hicks, C., T. McGovern, and C. Earl, Supply chain management: A strategic issue in engineer to order manufacturing. International Journal of Production Economics, 2000. 65(2): p. 179-190.

4. Amaro, G., L. Hendry, and B. Kingsman, Competitive advantage, customisation and a new taxonomy for non make-to-stock companies. International Journal of Operations \& Production Management, 1999. 19(4): p. 349-371.

5. Bertrand, J. and D. Muntslag, Production control in engineer-to-order firms. International Journal of Production Economics, 1993. 30: p. 3-22.

6. Braiden, P., N. Alderman, and A. Thwaites, Engineering design and product development and its relationship to manufacturing: A programme of case study research in British companies. International journal of production economics, 1993. 30: p. 265-272.

7. Gosling, J. and M.M. Naim, Engineer-to-order supply chain management: A literature review and research agenda. International Journal of Production Economics, 2009. 122(2): p. 741-754.

8. Hicks, C., T. McGovern, and C.F. Earl, Supply chain management: A strategic issue in engineer to order manufacturing. International Journal of Production Economics, 2000. 65(2): p. 179-190.

9. Little, D., et al., Integrated planning and scheduling in the engineer-to-order sector. International Journal of Computer Integrated Manufacturing, 2000. 13(6): p. 545-554.

10. Willner, O., et al., Globally Distributed Engineering Processes: Making the Distinction between Engineer-to-order and Make-to-order. Procedia CIRP, 2014. 17: p. 663-668.

11. Hicks, C., T. McGovern, and C.F. Earl, A Typology of UK Engineer-To-Order Companies. International Journal of Logistics: Research and Applications, 2001. 4(1): p. 43-56.

12. Willner, O., et al., Exploring the archetypes of engineer-to-order: an empirical analysis. International Journal of Operations \& Production Management, 2016. 36(3): p. 242-264. 
13. Amaro, G., L. Hendry, and B. Kingsman, Competitive advantage customisation and a new taxonomy for non make-to-stock companies. International Journal of Operations \& Production Management, 1999. 19(4): p. 349-371.

14. Wikner, J. and M. Rudberg, Integrating production and engineering perspectives on the customer order decoupling point. International Journal of Operations \& Production Management, 2005. 25(7): p. 623-641.

15. Bogus, S.M., K.R. Molenaar, and J.E. Diekmann, Concurrent Engineering Approach to Reducing Design Delivery Time. Construction Engineering and Management ASCE, 2005. 131(11): p. 1179-1185.

16. Maier, A.M., et al., Exploration of Correlations between Factors Influencing Communication in Complex Product Development. Concurrent Engineering, 2008. 16(1): p. 37-59.

17. Mello, M.H. and O.J. Strandhagen, Supply chain management in the shipbuilding industry: challenges and perspectives. Journal of Engineering for the Maritime Environment 2011. 225 (3): p. 261-270.

18. Terwiesch, C., C.H. Loch, and A. De Meyer, Exchanging Preliminary Information in Concurrent Engineering: Alternative Coordination Strategies. Organization Science, 2002 INFORMS 2002. 13(4): p. 402-419.

19. Kraljic, P., Purchasing must become supply management. Harvard business review, 1983. 61(5): p. 109-117.

20. Gelderman, C.J. and A.J. Van Weele, Purchasing portfolio models: a critique and update. Journal of Supply Chain Management, 2005. 41(3): p. 19-28.

21. Hesping, F., Tactics at the category level of purchasing and supply management: sourcing levers, contingencies and performance. 2015.

22. Hesping, F.H. and H. Schiele, Purchasing strategy development: A multi-level review. Journal of Purchasing and Supply Management, 2015. 21(2): p. 138-150.

23. Hesping, F.H. and H. Schiele, Matching tactical sourcing levers with the Kraljič matrix: Empirical evidence on purchasing portfolios. International journal of production economics, 2016. 177: p. 101-117.

24. Hesping, F.H. and H. Schiele, Sourcing tactics to achieve cost savings: developing a formative method of measurement. International journal of procurement management, 2016. 9(4): p. 473-504.

25. Ketokivi, M. and T. Choi, Renaissance of case research as a scientific method. Journal of Operations Management, 2014. 32(5): p. 232-240.

26. Voss, C., Case research in operations management, in Researching operations management. 2010, Routledge. p. 176-209.

27. Eisenhardt, K.M. and M.E. Graebner, Theory building from cases: Opportunities and challenges. Academy of management journal, 2007. 50(1): p. 25-32.

28. Yin, R.K., Case Study Research: Design and Methods. 2009: SAGE Publications. 